\title{
Customer Relationship Management (CRM) As An Innovative Element Of Direct Marketing And Its Impact On Market Performance. A Strategy To Personalize Market Massification Creating A Change In The Culture Of Management With The Client: A Focus To Increase Company Profitability Through The Development Of Customer Loyalty And Knowledge
}

Alejandra Costa Aizcorbe, Universidad Anáhuac, México

\begin{abstract}
Customer Relationship Management (CRM), is the central focus of this investigation. Speaking of CRM is not speaking about technology, just as speaking of hospitality is not laying a" Welcome" mat at an entrance. This investigation's theme sustains its importance in the quest for company profitability through the development of customer loyalty and knowledge and by implementing CRM processes that may work as value engines and at the same time be specific actions aimed at achieving cultural changes in customer management. Therefore, the investigation in Mexico has a central focus on companies where knowledge of the client and direct contact with him is the very reason of the companies' existence. Based on this, one searches for a concrete solution through an integrate model which one may service a conglomerate of firms in the Mexican corporate sector through a satisfying and profitable commercial mix for the companies' profile which is the objective of this work. With this investigation, it will be demonstrated that CRM processes can generate a change in the culture of client management and create a new focus within organizations to optimize the effort of direct commercialization, generating profitability based on customer loyalty and knowledge. With the development of this thesis a greater academic emphasis is placed in this area of marketing that seeks to demonstrate that the application of CRM processes within the field of direct analytic marketing in the Mexican market is a cornerstone in company profitability and the search for value.
\end{abstract}

\section{INTRODUCTION}

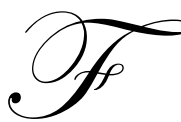

or a long time companies saw their clients only as transactions, focusing their efforts on everything that surrounded the customer but without ever actually getting to the customer; there was a "field force" of sorts around them. Companies' marketing departments occupied themselves by satisfactorily covering all these "distant proximity" points with the client: a product of operationally functional value (often nothing else than that according to companies), at an accessible price, in an excellent place and always surrounded by publicity strategies and massive promotions, but respecting the dividing line between clients and companies with the 
understanding that "they" represented desirable and profitable transactions that could be identified through codes and control numbers.

With time and the increase of competitiveness other strategies were employed to penetrate this customer field force, "compromise" and "loyalty" were discovered to be viable alternatives, giving way to "Loyalty Programs" (fundamental area of analysis in this study) and likewise the "Marketing of Relations" emerged, which would in the future lead to Customer Relationship Management and from this moment, the culture of customer management has evolved radically, greatly altering most operation, promotion, publicity and sales tactics, thus breaking multiple paradigms.

CRM and loyalty programs are concepts that today are well known in the country's marketing and technology fields, but even so in many cases they have not been understood in their entirety nor treated correctly in their application.

Be it as it may, two types of loyalty programs emerged: one is to boost sales and utilities, and to increase the range of products the company sells. The second type is more defensive, aiming at creating a closer bond between brand and the actual clients, with the goal of maintaining the client base (Uncles, Dowling y Hammond, 2003).

An important component of loyalty programs is the reach of cross selling, which implies that clients can be motivated to buy products that they normally would have not purchased from the seller (Uncles et al. 2003).

Nevertheless, the reading of this intelligent segmentation and its correct use must be cleared by the company's upper management based on a marketing philosophy which must stop seeing the client as a number, in order to look for a closer relationship in a respectful and equal friendship, based on a win-win relationship founded on taste, necessity, behavior and lifestyle knowledge.

As one of its fundamental cornerstones, CRM-like loyalty programs adhere to Pareto's law ${ }^{1}$, which establishes that $80 \%$ of corporate income derives from only $20 \%$ of customers, which explains the company's focus on loyal customers (Mcllroy and Barnett, 2000). These are the clients that deserve much more investment of attention, time and money than the rest, insisting very strongly on assigning fewer resources on maintenance and perfection of the client mass and on the generation of new clients. Past investigations strengthened the assertion that the benefits of retaining and maintaining clients has a direct impact on the company's profits and also sustained that it can be five times more expensive to obtain a new client than to keep a current customer (Mcllroy and Barnett 2000).

For Mexican companies that have labored for years to find new clients and attend to the masses, these reductive and "dangerous" concepts are rarely taken into consideration, since a lack of culture of client knowledge exists partially motivated by the Mexican's need to pass unnoticed in certain aspects of his life, argument that takes us to a grave fundamental problem, since databases are the very life source of loyalty programs and other CRM applications and it is very difficult to generate, maintain, and update in a society for which this represents an enormous cultural change.

The identified problems are:

1. The CRM is not considered within the Administration as an innovative element of Direct Marketing since this has not been proven.

\footnotetext{
${ }^{1}$ Dr. Joseph Juran coined the name Pareto in honor of the Italian economist Vilfredo Pareto (1848-1923) who conducted a study on the distribution of wealth, in which he discovered that the minority of the population possessed the majority of wealth, while the majority of the population possessed the minority of wealth. With this observation he established "Pareto's Law" which arguments that economic inequality is inevitable in any society.

Dr. Juran applied this concept to quality, obtaining what to day is known as the $80 / 20$ rule. According to this concept, if there is a problem with many causes, one can argument that $20 \%$ of causes resolve $80 \%$ of the problem and that $80 \%$ of causes only resolve $20 \%$ of the problem.

Thus, Pareto's Analysis is a strategy that separates the "vital few" from the "trivial many".
} 
2. Direct Marketing in Mexico has been surpassed by the market's dynamic and by its massification, by which companies need to evolve in their customer management strategies to become competitive and to generate sustained profitability.

3. In Mexico, CRM has been underemployed, something which has not occurred in other countries where this element of Direct Marketing has proven to be very effective in strengthening companies competitiveness.

4. The adequacy of CRM processes has not been studied in its totality in Mexico; therefore, companies do not dispose of an adequate focus in this tool of Direct Marketing to help them impact the performance of their markets. This is due to the fact that in Mexico there is scant investigation on the potential and limitations of this technique and its correct implementation for Mexican companies to dispose of a competitive element in their organizations.

5. Otherwise, CRM's two key issues are the development of customer loyalty and knowledge and therefore companies' databases, both themes still undeveloped in Mexico, due to a lack of reliable detection, measurement, follow-through, and potentialization tools of customer loyalty working in the country, nor are databases created with the necessary quality levels for a correct One-on-One marketing based in knowledge of the customer.

\section{METHODOLOGY}

This study aims at responding key questions in the Mexican setting:

Frame 1: Central Question of the Investigation. March 2005

\begin{tabular}{|l|}
\hline \multicolumn{1}{c|}{ Central Question } \\
\hline How To Professionalize The Implementation Of CRM Processes In Mexico? \\
\hline Actual situation: \\
There is little knowledge of the topic; as a result variables for a correct implementation of CRM processes remain \\
unknown. \\
Most implementations are based on foreign methodologies; therefore an appropriate methodology of strategies \\
implementation is inexistent in Mexico. \\
There is an overvaluation of new ("fad") tools and marketing strategies in constant evolution across the globe, which \\
impedes companies from committing themselves to a long-term strategy, companies which in their frustration then \\
tend to once more change strategies. \\
Due to the continued economic crisis, companies are more preoccupied with solving operations than investing in \\
strategy. \\
Resistance to change exists, generating a competitive disadvantage for companies of direct commercialization which \\
have not applied CRM processes with respect to the market.
\end{tabular}

Complementary questions:

Given the investigation's central theme, two basic questions are posed in order to answer the principal problem.

1. How to generate reliable customer loyalty tools of detection, measurement, follow-through, and potentialization that function correctly for companies in Mexico?

Actual situation:

- $\quad$ This theme has not been properly investigated in Mexico leading to decision-making base on parameters that do not reflect the true behavior of the domestic market.

- Loyalty has not proven to be a catalyst of profitability in Mexico, causing an absence of solid negotiation bases to convince upper management to invest in loyalty to their clients. 
- A culture of long-term customer documentation and follow-through does not exist in the marketing strategies currently implemented in the country, forcing a start from "zero" when it comes to implementing this type of strategies.

2. How to generate a database with the required quality levels for the development of a correct One-on-One marketing base on customer knowledge in Mexico?

Actual situation:

- Companies do not have a culture of database recollection and exploitation, and those that they do count on are not appropriate for implementing CRM processes.

- Mexicans tend to be untrustworthy of others, thus are not always willing to give out personal information, resulting in a lack of information necessary to correctly and directly approach the objective market.

- Adequate strategies, tools, and technologies have not been implemented for the recollection, storing, managing and exploitation of databases in Mexican companies, this databases (which are the principal assets of CRM strategies) have too many errors, which are reflected in the results obtained (for that which comes in, comes out).

The previous questions led to the central theme of this investigation and to the specific objectives of the above mentioned investigation:

\section{Frame 2: General Objective} March 2005

\section{General Objective}

Prove that the Customer Relationship Management (CRM) is an innovative element that enriches Direct Marketing as an area of knowledge within the Administration.

Prove that through the implementation of CRM processes, a strategy of massive personalization is generated, creating a change in the culture of customer management based on the development of client loyalty and knowledge that will lead Mexican companies to generate greater profitability.

Prove that the above mentioned is achieved by developing customer loyalty and knowledge, strengthening both with correct database management.

\section{Specific Objectives:}

- $\quad$ Revise the models and definitions that have been generated to conceptualize CRM processes.

- $\quad$ Analyze the variables that have been proposed to define CRM processes.

- $\quad$ Evaluate the most important operational definitions and diagnostic instruments that have been developed for different CRM strategies.

- $\quad$ Detect the variables that have influenced results in CRM processes and strategies in Mexican industry.

- Measure the client's response to these initiatives and/or companies.

- $\quad$ Identify and evaluate a Mexican company whose business model is based on the development of customer knowledge and loyalty.

- Demonstrate that massive personalization generates an organizational change in the culture of customer management.

- $\quad$ Propose a focus to optimize the effort of Direct Marketing in Mexico, generating profitability based on the development of customer loyalty and knowledge.

- Develop and validate a methodological guide applicable to Mexican companies that look to create profitability through the lens of Direct Marketing and the implementation of CRM processes. 
Once stated the investigation's problem and objectives, the following hypothesis was generated:

\section{Frame 3: Investigation Hypothesis. March 2005}

\section{Hi:Investigation Hypothesis.}

Customer Relationship Management (CRM) is an innovative element that moves and broadens the knowledge of Direct Marketing and thus Management's knowledge, which generates value for companies and proposes tools that its administrators can employ to bolster the organizations' competitiveness.

The correct implementation of CRM processes as a strategy of massive personalization optimizes the efforts of Direct Marketing in companies basing themselves in the development of customer loyalty and knowledge, creating a change in the culture of customer management which generates sustained profitability in the organization.

In parallel with the hypothesis, the principle independent and dependent variables in the investigation were detected, variables which are illustrated in the following pyramid of conceptual hierarchies:

Diagram 1: Pyramid Of Conceptual Hierarchies.

May 2005

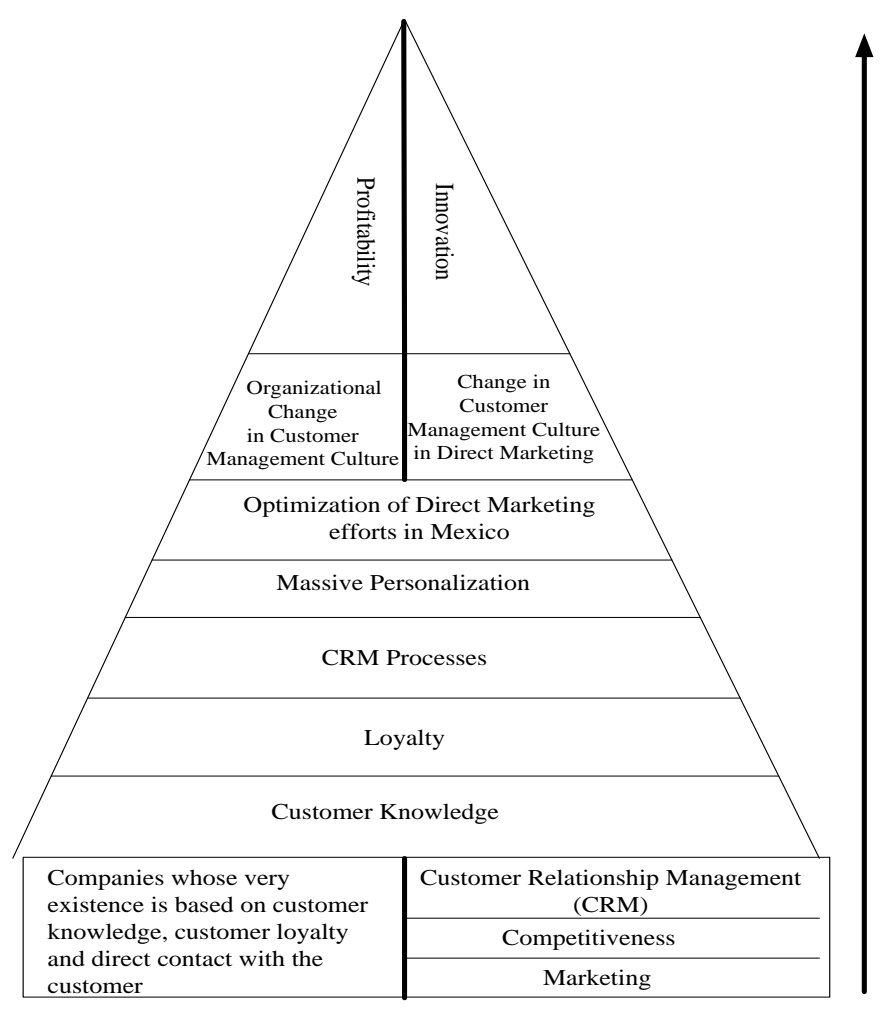


Once the variables and hypothesis have been analyzed, it is defined that a technological structure, customer knowledge and correctly developed and managed database, generate loyalty; which with the implementation of CRM processes lead to the implementation of new massive personalization strategies which lead to the optimization of Direct Marketing efforts in Mexico. The most important of all this, is that the above mentioned is a process of continual improvement which leads to a change in the culture of customer management which results in company profitability and innovation in Direct Marketing. This process is reflected in the following diagram

\section{Diagram 2: Multivariate Complex Causal Structure}

May 2005

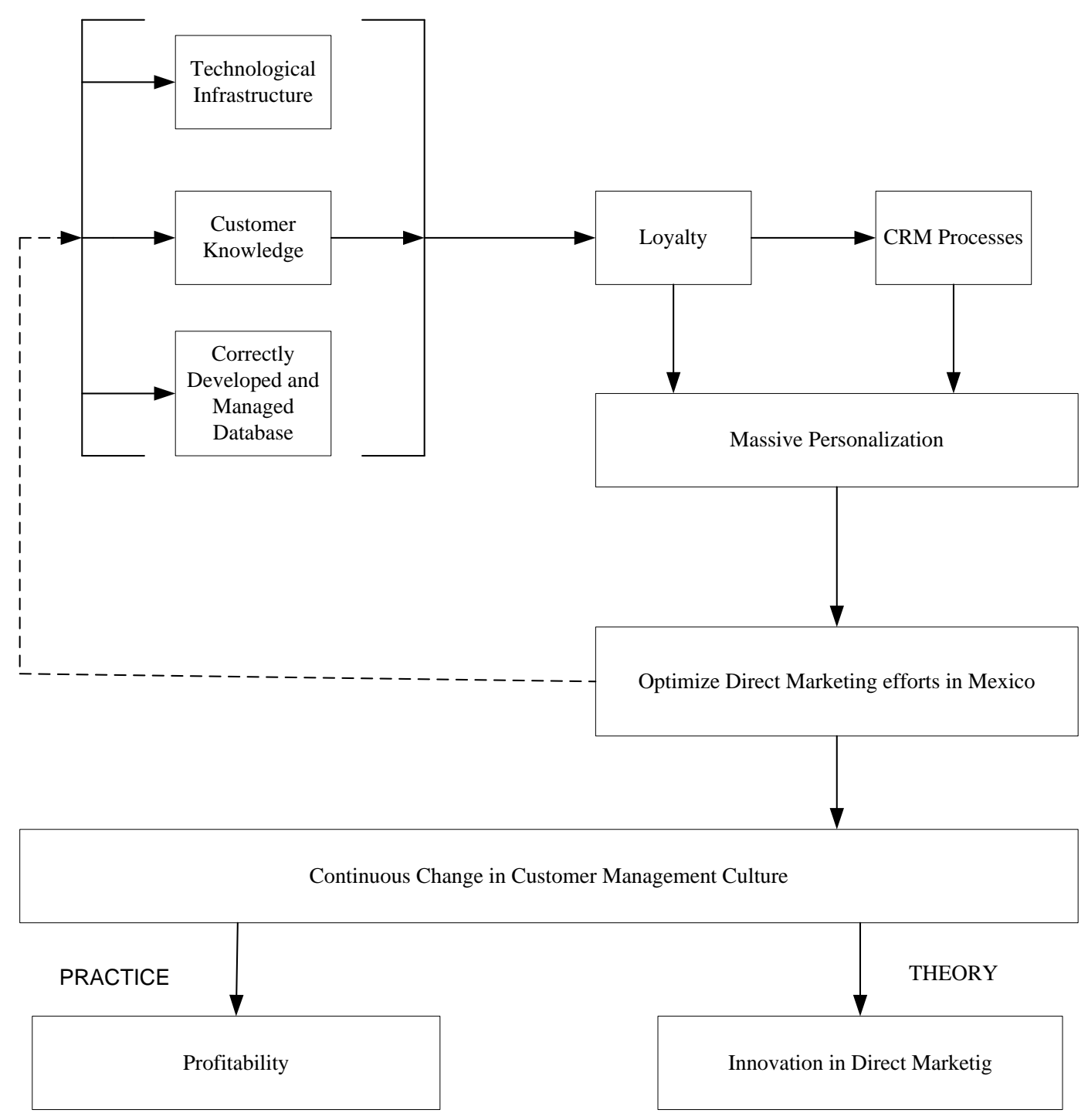




\section{DEVELOPMENT}

According to Hernández, Fernandez and Baptista (2002), the qualitative focus is based on an inductive scheme which is expansive, individual, which does not numerically measure phenomenon, nor does it have as an end goal to generalize the results of its investigation, it does not carry out a statistical analysis, its method of analysis is interpretative, contextual, and ethnographic.

In the particular case of this work, in its first stage, the investigation follows a model of dominant focus; such a focus is qualitative, since it begins with an explorative investigation along with a descriptive investigation using an inductive expansive scheme for its conceptualization.

In a second phase within this initial stage, a quantitative component will be added, given that it will be based on empiric generalizations (proposals that have been backed in most of the conducted investigations) (Hernández et. al., 2002), which are applied to the problem of study, and therefore is of a deductive nature since it intends to compare initial conclusions with settings already existent in the area.

The purpose of this study is to identify concepts or promising variables that intervene in the implementation of CRM processes in Mexico, to achieve this goal certain questions are posed with respect to the investigation. Based on the actual knowledge of the topic abroad that the revision of literature reveal us, it is stated that the study in its beginning is exploratory, given that the objective is to discover which variables are possible and how these behave in a specific sector in a country where they have practically not been studied. In few occasions exploratory studies constitute an end in themselves, generally they determine tendencies, identify areas, ambient, contexts, and situations of study, possible relations between variables; or establish the "tone" of more elaborate and rigorous investigations to follow (Hernández et al., 2002).

From a scientific vantage point, to describe is to measure or recollect data by which the present investigation also possesses a descriptive character, since during the investigation there is also the possibility that literature reveals that there are more "bits and pieces" of theory with moderate empirical support, in other words, descriptive studies that have detected and defined certain variables. A descriptive investigation seeks to specify important properties, characteristics, and traits of any phenomenon to be analyzed (Hernández et al., 2002).

The initial procedure to recollect information occurs through a greater search (vertically deepening the area), interviews with experts and responsible of the principal CRM processes and loyalty implementation programs in Mexico, analysis of quantitative and qualitative indicators (the latter through relations with news, reports, and interviews) and the proper observation and induction corresponding to the opinion of some clients of the given strategies.

The result of this first stage leads us to the second stage of the investigation where a Panel Type Longitudinal Design (soon to be described) is employed for fieldwork.

The analysis technique can be resumed in a graphic conceptual manner in the following diagram, where the investigation's focus is followed along with the different schemes the investigation is based on to reach a definitive design. 


\section{Diagram 3: Investigation Design}

May 2005

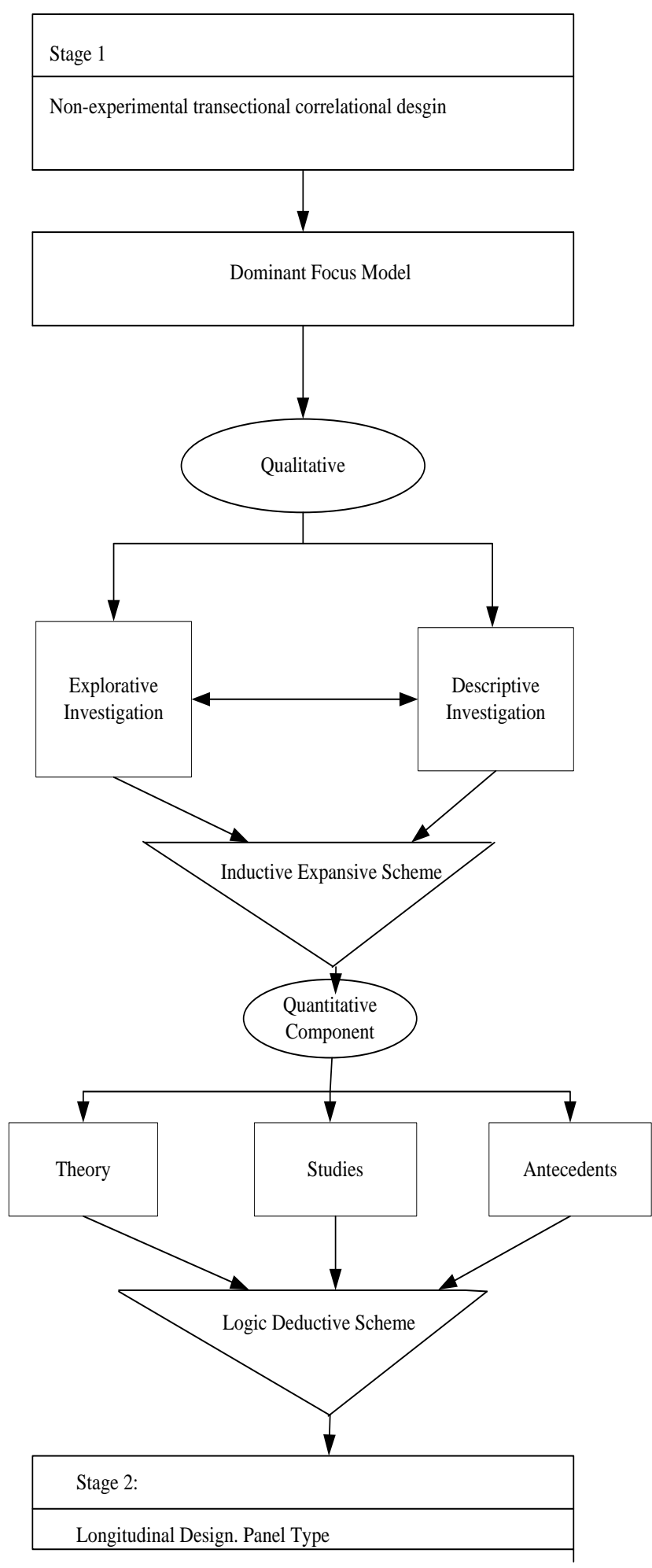




\section{Field Work}

A. Recollection And Data Analysis - Panel created by Alejandra Costa May 2005

Quasi-experimental design (with intact groups) of chronological series with multiple treatments and stimulus repetition (with pre and post examinations). A greater of accuracy will be achieved through the process.

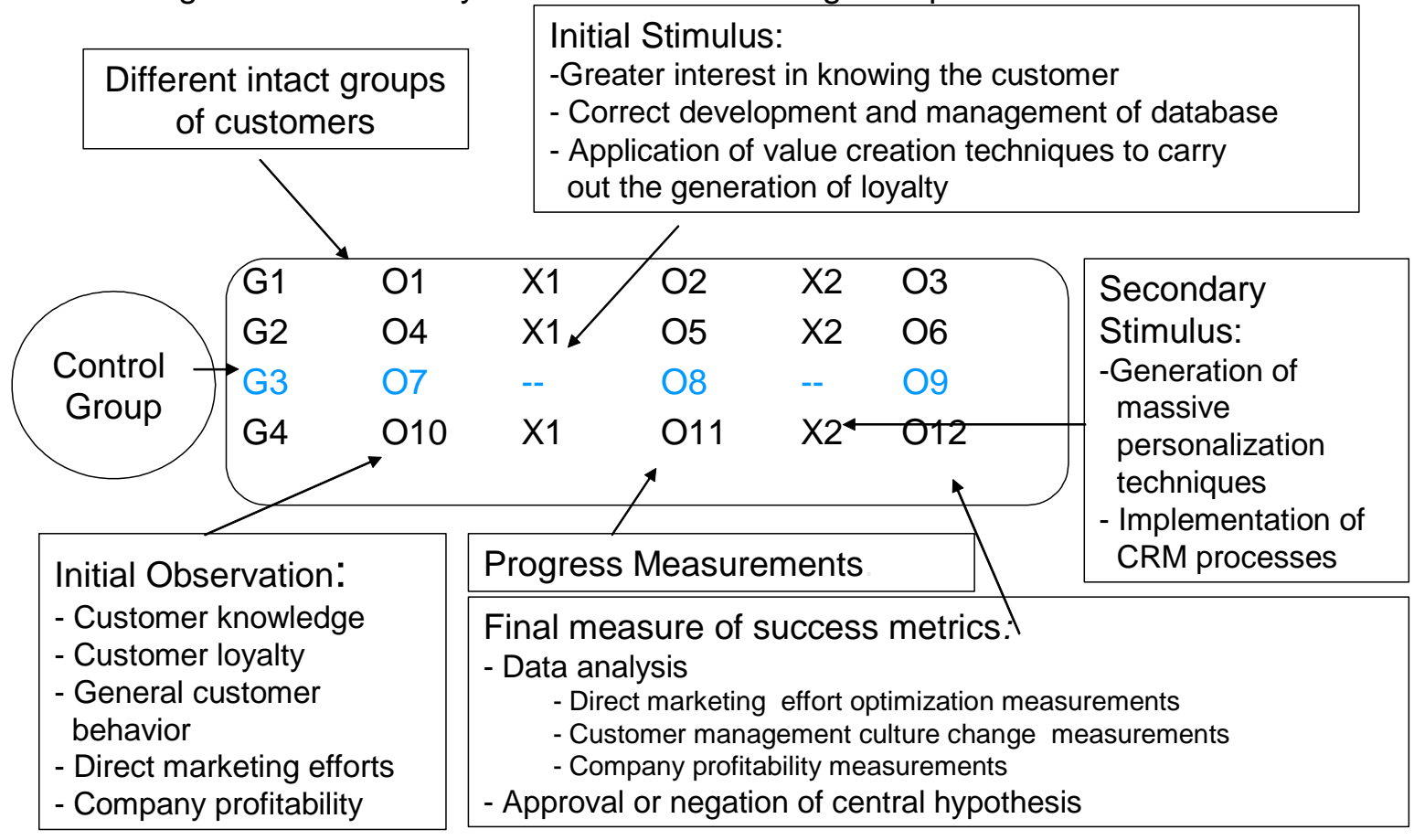

\section{B. Information Technology Used}

Information Technology is based on a Business Process Management System, BPMS.

A BPMS tool not only involves managing processes within an organization but also integrating these in real time with client and provider processes. The ultimate idea behind a BPMS is to create cohesive whole of processes, people and technology.

The tool to manage these processes, of course including CRM processes, is Bizagi, a tool that already counts with installations in Latin America and Europe. This tool allows one to automate organization processes and to control these processes (monitoring, supervising, informing on misdirect ions, scale attribution levels, take action and report results).

Bizagi's principal nucleus is constituted by a "Dynamic Work Flow Machine", which models automatic decisions and establishes flexible rules to distribute necessary tasks to the required personnel or processes at the most precise moment. 
This is the best type of tool that can be used in CRM implementations, thanks to the flexibility it offers in program changes and in the integration of customer and supplier applications and data.

\section{EXPECTED RESULTS}

After revising the state of the art which is displayed in the following table:

Table 1: Revision Of The State Of The Art. May 2005

\begin{tabular}{|c|c|c|}
\hline Variables & CRM Models & Requirements \\
\hline $\begin{array}{l}\text { Objective: } \\
\text { Validate and Standardize. }\end{array}$ & $\begin{array}{l}\text { Objective: } \\
\text { Determine Perspective and Focus. }\end{array}$ & $\begin{array}{l}\text { Objective: } \\
\text { Unify Implementation Criteria. }\end{array}$ \\
\hline $\begin{array}{l}\text { - Customer Knowledge and Loyalty. } \\
\text { - CRM and Massive Personalization } \\
\text { - Direct Marketing and Customer } \\
\text { Management Culture. } \\
\text { - Profitability and Innovation. }\end{array}$ & $\begin{array}{l}\text { 1.- Customer Loyalty and its programs } \\
\text { (Uncles, Dowling and Hammond, } \\
\text { 2002): } \\
\text { - Monogamous (Commitment). } \\
\text { - Polygamous (Acceptance). } \\
\text { - } \quad \text { Promiscuity (Purchase). } \\
\text { 2.-Loyalty Programs, } \\
\text { - Strategies and Practices (Meyer- } \\
\text { Waarden and Benavent, 2001): } \\
\text { - Customer Relationship } \\
\text { Management. } \\
\text { - Management of Customer } \\
\text { Heterogeneity. }\end{array}$ & $\begin{array}{l}\text { - } \text { Technological Infrastructure. } \\
\text { - } \text { Customer Knowledge } \\
\text { - } \quad \text { Developed Databases }\end{array}$ \\
\hline
\end{tabular}

To determine the potential and limitations of the investigation, which are detailed as follows:

Table 2: Potential Y Limitations Of The Investigation May 2005.

\begin{tabular}{|l|l|l|}
\hline Investigation Concept & Factors Included & Factors Excluded \\
\hline Application Setting. & Mexico. & Abroad/Foreign. \\
\hline Company type. & Companies focused on Direct Marketing. & Massive Marketing companies. \\
\hline Company size. & Small, Medium, and Large. & Micro and Macro companies. \\
\hline Fundamental Elements in fieldwork. & Customer Loyalty and Knowledge. & Macro and Microeconomic factors. \\
\hline Academic Setting. & $\begin{array}{l}\text { Competitiveness } \rightarrow \\
\text { Direct Marketing } \rightarrow \text { Marketing } \rightarrow \text { Management. }\end{array}$ & Other Management areas. \\
\hline
\end{tabular}

Expected results and contributions once the investigation has been finalized can be seen schematically and in a general manner in the following figure: 
Diagram 6: CRM Contributions To Mexico.

May 2005

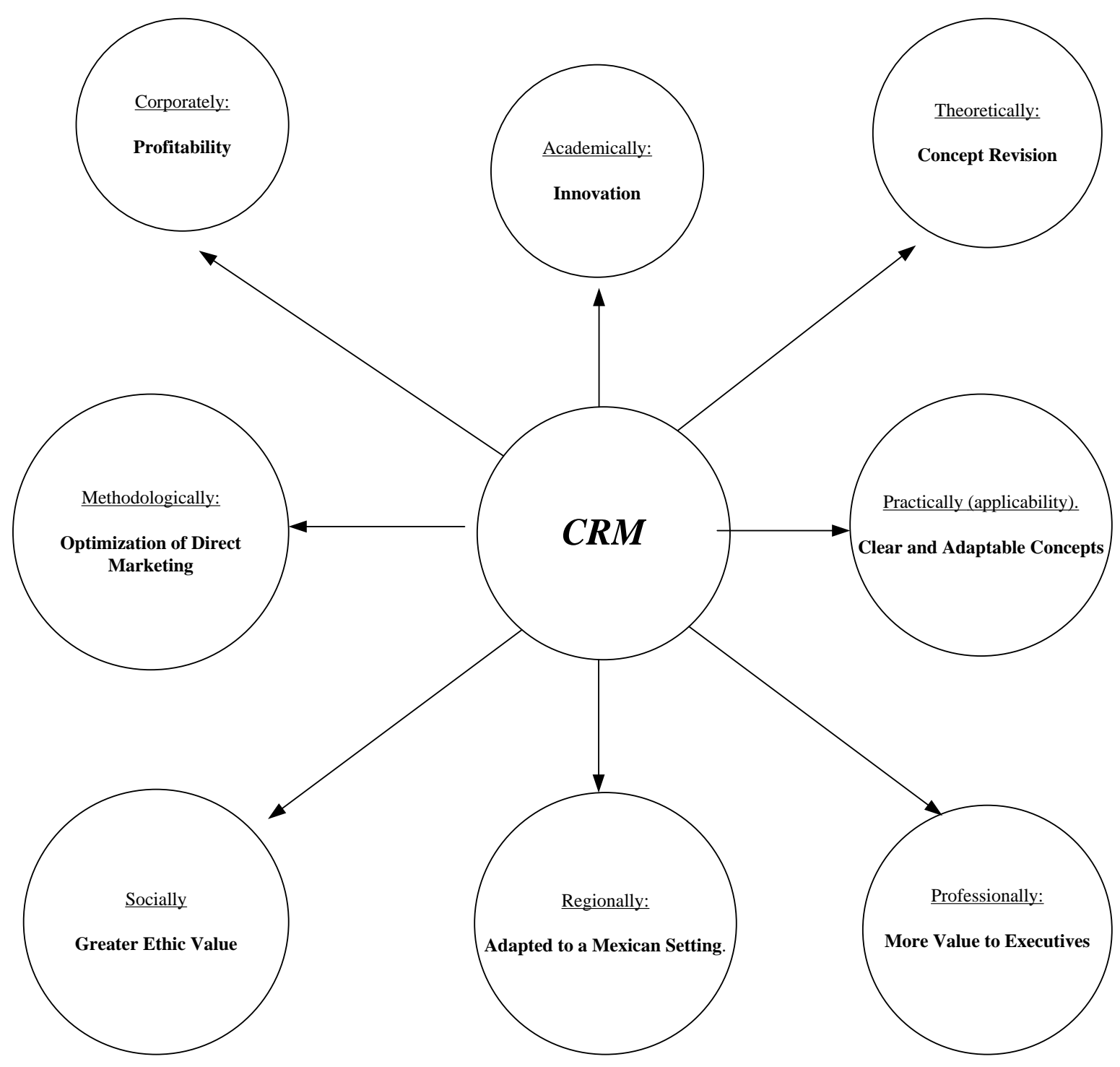

Which will be achieved by implementing the investigation on the Afición Fútbol company, sponsor of the project as well as owner and creator of the "Club América" Football loyalty program, group belonging to Televisa, firm that counts with 175,000 registered clients, making it the largest Football Loyalty Club in the world and a fertile field for the implementation of CRM processes.

As proven in this presentation, an actual developing case is illustrated with solid feedback and evaluation of successful readings until mid-2007. However, this document clearly demonstrates that the academic society, although often distant from direct marketing activities in the business community, can explore and provide powerful tools to this vital, key corporate activity. 
Compared with other administrative functions, direct marketing has been ignored, dependent more on the initiatives of professional executives that possess great experience but scant methodological support, instead of proven academic methods to optimize CRM efforts.

Therefore, this document must be seen as an open invitation to the academic society to focus its attention on this vital activity, and to permit the marketing community to put aside "homemade" solutions in order to avoid uncertainty in its particular direct marketing setting with tools and methodologies that stand up to the greatest academic standards.

\section{REFERENCES}

1. Barber Kuri, Carlos Miguel. Lozano Chávez, José. (2003). Implicaciones de internet y el intercambio B2BB2C. El Financiero. Artículo. Año XXII; No. 6375; Sección Negocios. México. P. 30.

2. Barber Kuri, Carlos Miguel. (2005). Megatendencias. En Revista Integra. No. 6. Universidad Anáhuac del Sur. México.

3. Barber Kuri, Carlos Miguel. (2005). Industrias representativas de América, Europa y Asia. Ed. Miguel Ángel Porrúa-UAS. México.

4. Barber Kuri, Carlos Miguel. (2005). Casos empresariales. Tomo II. Ed. Miguel Ángel Porrúa -UAS. México.

5. Enriquez Monroy, Eduardo. (2004). Propuesta de Implantación de CRM en una empresa de banca-seguros en la República Mexicana. Tesis. ULSA. México.

6. Hernández, R., Fernández, C. and Baptista, P. (2002). Metodología de la Investigación (3a . Edición), México, D.F., Ed: McGraw-Hill Interamericana.

7. Mcllroy, A. and Barnett, S. (2000). Building customer relationships: do discounts cards work?, Managing Service Quality, vol. 10, pp. 347-355.

8. Meyer-Waarden, Lars and Benavent, Christophe. (2001). Loyalty Programs: Strategies and Practice. Education and ReseCRMh Day, FEDMA, Madrid, 14 September.

9. Uncles, M.D., Dowling, G.R. and Hammond, K. (2003). Customer loyalty and customer loyalty programs, Journal of Consumer Marketing, vol. 20, no. 4, pp. 294-316. 